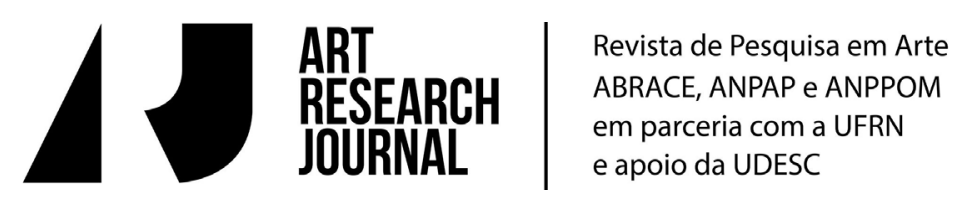

\title{
Olhares sobre a ausência/presença: teatro e tecnologia
}

\author{
Felisberto Sabino da Costa \\ Ipojucan Pereira da Silva \\ Colaboradores: Cristiane de Fátima Martins \\ Winston Kurtz \\ O CÍRCULO/Grupo de Estudos Híbridos das Artes da Cena \\ Universidade de São Paulo, Brasil
}

\section{Proposições para uma conversa}

As transformações concernentes à ausência/presença, que ora vivenciamos na cena contemporânea, têm como possíveis disparadores a virada sociocultural, de efeitos globais, no decorrer do século XX. O surgimento de novas mídias altera o posicionamento do sujeito e sua percepção como indivíduo e membro social de uma coletividade, provocando mudanças na percepção estética, tanto para quem vê a obra como para quem a produz. Desse modo, na contemporaneidade, temse experenciado uma inversão de papéis, o espectador se mostra cada vez mais ativo, tornando-se parte da obra, sendo capaz de transformá-la. Se o espectador está cada vez mais presente no jogo proposto pelo artista, este tem buscado na ausência a sua forma de atuação.

A manipulação/utilização/produção de dispositivos e tecnológicos propõe múltiplos jogos de onde podem advir experiências lúdicas ou aventar outras questões ainda não vivenciadas. A incorporação de tablets, celulares, laptops, telas, projetores e demais aparatos compõe paisagens sonoras e visuais que se convertem em materiais intrínsecos de uma dramaturgia, atuando não apenas como objetos cenoplásticos. Manipular esses dispositivos é colocar-se numa zona conflitiva em que a falha - um modo de experienciar a ausência - é um dado que permeia todo o jogo. A presença (intangível) de imagens redimensiona o tocar que adquire outros estatutos, como, por exemplo, a eclosão do olho tátil. Entra-se numa zona ambígua em que operar dispositivos é também ser operado por eles. A liberdade nessas manobras situa-se num território em que há certas consignas para que o aconteci- 
mento se instaure. Há determinados campos de tensões que devemos aceder, leis que devemos aquiescer para que o jogo aconteça. Não se trata de aparelhos inertes, seja pela sua própria estrutura seja pelo que o aparato tecnológico implica, manuseia-se o aparelho, e por extensão, a imagem. Um objeto propõe toda sorte de manipulação, na qual devemos demarcar territórios, configurar atitudes, tecer relações que, em determinados contextos, são compostos de ações programadas. Aflora-se uma ausência que propõe ao espectador ser um atuante, numa ambiência que pode se abrir indefinidamente, com a possibilidade de escapar e navegar em outras paragens.

A vida própria que cada objeto congrega é negada, ele é programado para realizar determinadas funções na cena. A presença dos corpos por intermédio das imagens, das vozes ou de outros artifícios, às vezes, liga-se a um programa ao qual o espectador não pode não escolher. Há casos em que a única possibilidade de não aceitar é desligar o botão, promovendo a desconexão com o objeto. Os dispositivos convidam ao jogo, a experimentar relações de toda ordem, mas necessita-se domínio para lidar com as instruções postas para tal. Tato e contato confundemse, o manejo do aparato (dis)põe distintas ações corporais.

Esse artigo busca discutir essas questões abordando três aspectos desse universo complexo: o texto como dispositivo tecnológico, a mescla do corpo com imagens através do uso de máscaras videográficas e a espacialidade cênica como recurso poético. Permeando as três instâncias, a presença do espectador como participante ativo.

\section{Texto, dispositivo e tecnologia}

A escritura que se destina hoje ao teatro, conforme Danan, elabora-se sobre a franja entre "uma dramaturgia fragilizada e sua ausência ou sua quase ausência. Entre um teatro de puro texto material e aquele que busca manter um princípio dramatúrgico" (2012, p. 53). Seguindo essa trilha, podemos falar de um dispositivo dramatúrgico contemporâneo em que a tecnologia se situa não somente no manejo de objetos eletrônicos, mas no modo como a dramaturgia é composta: articulada num espaço em que vivo e inerte, máquina e humano não se assentam como dados antinômicos, emergindo como espaço aberto a todas as possibilidades. No sentido aqui empregado, o dispositivo dramatúrgico visa a um aconteci- 
mento como coisa, "mas uma coisa à qual adere ainda algo de outro" (Heidegger, 1998 , p. 12). Efetuando um deslocamento da abordagem heideggeriana sobre a obra de arte para o território da dramaturgia, diríamos que um dispositivo dramatúrgico promove uma abertura que desestabiliza a relação entre a terra e o mundo, colocando em questão o discurso cotidiano fundado na reprodução mecânica, no falar vazio que enrijece a vitalidade originária das coisas. Esse dispositivo convoca a ausência, pois revelar uma ação é ao mesmo tempo lidar com um ocultamento. Criar um dispositivo dramatúrgico é abrir fendas, um acontecimento em que "as coisas adquirem sua demora e sua urgência, a sua lonjura e a sua proximidade, a sua amplitude e a sua estreiteza" (Heidegger, 1998, p. 43). Abrir um espaço é criar um mundo e deixar a "terra ser terra [...]. A terra é aquilo que, por essência, se fecha. Elaborar a terra quer dizer: trazê-la ao aberto como aquilo que se encerra" (Heidegger, 1988, p. 44-45). Sob essa perspectiva, constituir um dispositivo dramatúrgico é simultaneamente fazer surgir um mundo e cuidar da terra. É desvelamento e ocultamento, é presença e ausência, pois "o mundo funda-se na terra e a terra irrompe pelo mundo" (Heidegger, 1998, p. 47). Ao dinamismo abrir/fechar poderíamos nominar ação.

Um texto-dispositivo não necessariamente precisa lidar com aparelhos, pois a tecnologia que o envolve também diz respeito à sua plasmação, ao modo de configurá -lo, às experiências que convocam vidas, à instauração de mundos, perfazendo um intricado de ações que envolvem a obra e também aquele que a faz. Dessa forma, por exemplo, nos dispositivos plásticos do artista Fred Eerdekens as palavras estão carregadas de ausência, o que não significa falta, mas um olhar através da sombra. O artista cria esculturas em que a sombra traz à luz manifestações ocultas, compondo uma linguagem não transparente, distanciando-se da "língua formal, puramente maquinal, operacional, destituída de qualquer ambivalência" (ByungChul, 2014, p. 12). A palavra traz em si a negatividade, a resistência necessária às injunções coercitivas que teimam em torná-la lisa, plana, sem espessura ou rugosidade. A palavra que emerge dessa ausência, a partir da sombra proveniente da luz projetada num objeto, congrega mundo e terra.

Em sua obra Life Itself Is Not Enough (Fig. 01) há um arranjo composto por roupas, vidro, aço e projetor de luz, de onde brota a palavra atravessada pela sombra, numa espécie de ausência que desvela a vida. Conforme o artista: "Quando as palavras são escritas (em oposição à fala), elas são usadas na ausência (e por causa 
da ausência) de outra coisa. Mais tarde, quando o texto for lido, será a ausência do autor. "Eerdenkens refere-se a Samuel Beckett como fonte de inspiração para suas criações. Em Beckett, a tecnologia não diz respeito apenas aos aparelhos e aos suportes midiáticos necessários à consecução da sua dramaturgia, mas ao próprio agenciamento do dispositivo dramatúrgico. Há um caminho, que compreende de En Attendant Godot (Esperando Godot) a Soufle (Respiração), no qual ausência(s) e tecnologia(s) vieram sendo experimentadas (vividas) pelo autor em distintas configurações dos seus dispositivos textuais. Ao dizer palavra (texto) poder-se-ia também aventar corpo e outros elementos mais.

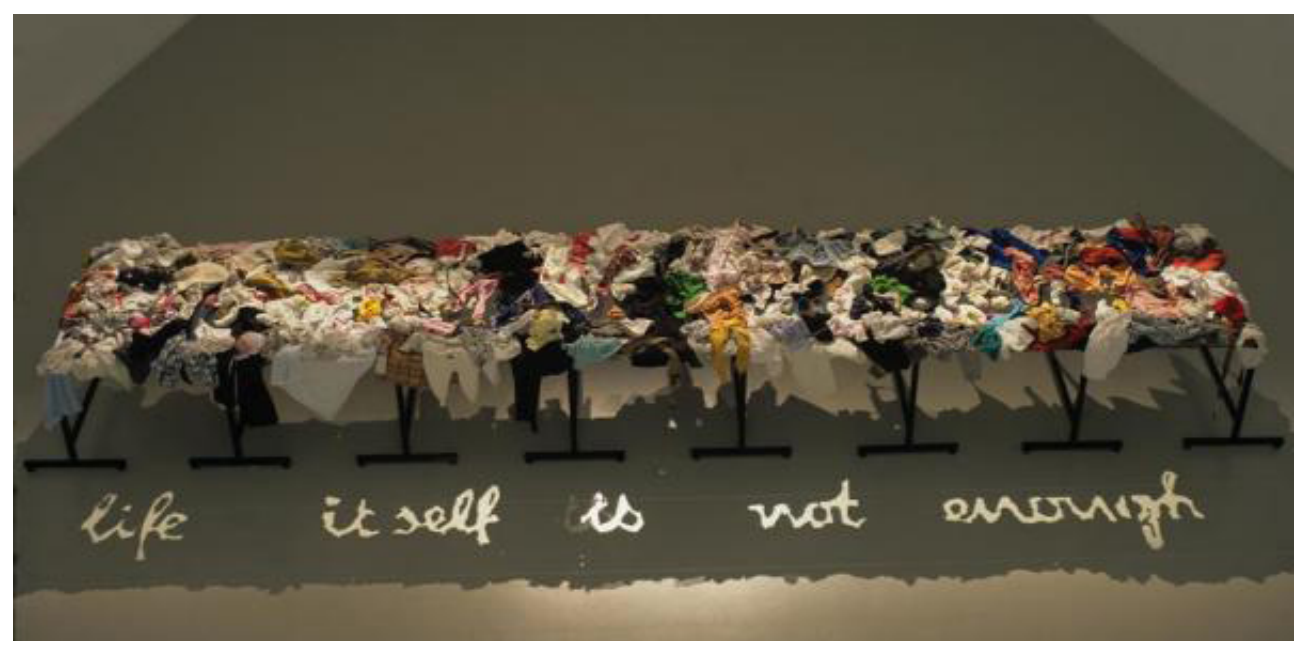

Fig. 01 - Life Itself Is Not Enough, Fred Eerdekens (1999), em http://www.magda-gallery.com/fr/life-itself-not-enough-fred-eerdekens

Um dispositivo dramatúrgico, ao empregar objetos tecnológicos, invoca as diversas mortes a que estamos submetidos no cotidiano. Somos instados ao exercício diário da descartabilidade, da transparência, situando-nos numa espécie de presença (presente) em que ausência rima com obsolescência por intermédio da escassez. Como nos diz Milton Santos:

O nosso tempo consagra a multiplicação das fontes de escassez, seja pelo número avassalador dos objetos no mercado, seja pelo chamado incessante ao consumo. Cada dia, nessa época de globalização, apresenta-se um objeto novo, que nos é mostrado para nos provocar o apetite (2001, p. 130-131) 
Compor um dispositivo dramatúrgico é lidar com a ausência no sentido de fazer "vir ao mundo o que originalmente escapa ao mundo, seu alicerce e seu fundo abissal" (Haar, 2007, p. 87). É configurar algo, através de uma linguagem que faz emergir o jogo entre velar (ausência) e desvelar (presença) que trafega em mais de um sentido.

\section{A pele como tela, a pele como simulação}

A tecnologia pode intensificar a relação ausência/presença, na medida em que os corpos tendem a perder o peso, convertendo-se em objetos voláteis, em imagens puras. Em artistas como o videoperformer Otávio Donasci e o diretor Denis Marleau, essa questão se amplia quando questionam os efeitos da hibridização homem-máquina.
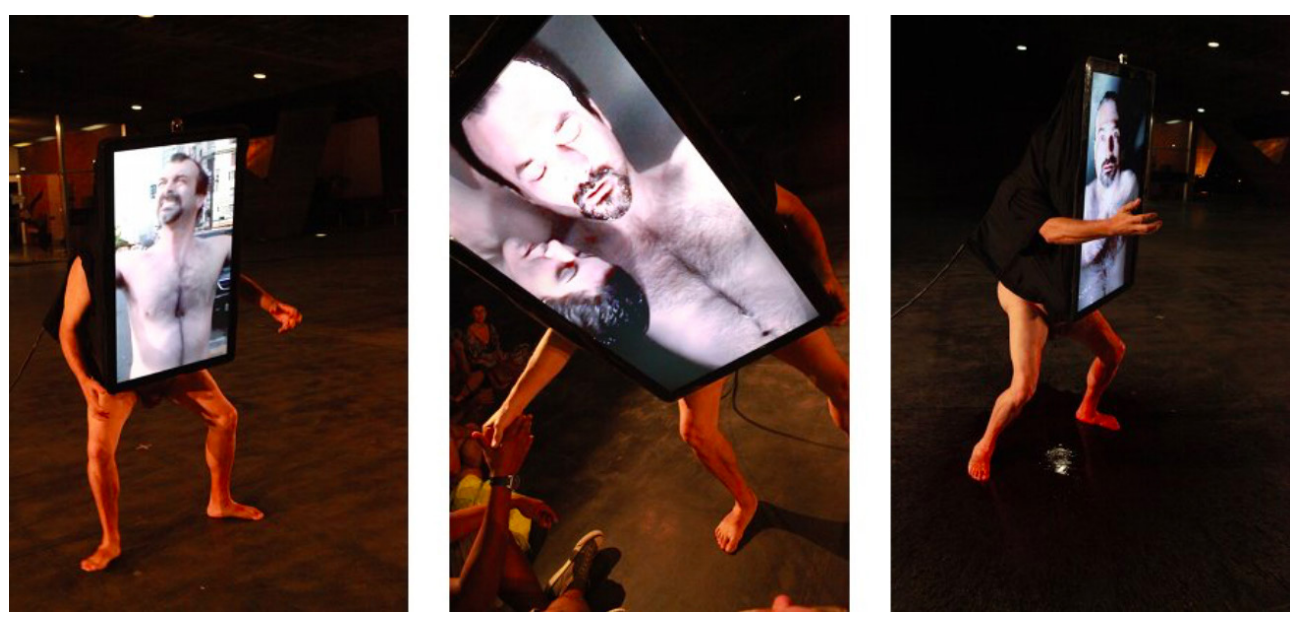

Fig. 02 - Videotango, Otávio Donasci, 2011), em http://www.performanceartebrasil.com.br/imagens/

Donasci cria uma atmosfera que expande as potencialidades humanas e exterioriza a conexão do ritmo biológico ao tecnológico. A conjunção corpo-imagem das videocriaturas (Fig. 02) transfigura a pele em tela, possibilitando a criação de um terceiro ser - um híbrido - mediante a comunhão corpo (presente) e rosto (ausente). As máscaras videográficas tornam-se espelhos ao oferecerem ao espectador momentos de estranheza e reflexão, associando o specimen (aparência, forma de) e o spectrum (espectro, aparição) com a tecnologia, potencializando no espaço a abstração do duplo.

A tela como pele simula e dissimula, oculta e exibe a reinvenção artificial dos 
sistemas de signos reais. Uma passagem que já não é do real, nem da verdade, mas do hiper-real que promove modelos simulados de possíveis realidades. Para Baudrillard, "a simulação nada mais é do que fingir não ter o que se tem", fazer parecer real, imitar. Já, dissimular é "fingir o que se não tem", suprimir a aparência daquilo que se quer ocultar (1981, p. 9). Tal duplicidade cria uma confluência estética, um corpo-imagem que é uma tentativa de nos devolver a consciência das limitações do controle humano sobre o próprio corpo, diante dos hibridismos tão sobejados pelas correntes pós-humanas.



Fig. 03 - Les Aveugles - Les Fantasmagories Technologiques, Denis Marleau,2009, em http://www.Ihebdoduvendredi.com/article/9011/les_aveugles_ou_quand_ technologie_rime_avec_dramaturgie

Se para Donasci o mascaramento tecnológico se pauta na dualidade do corpo (presente) e no rosto (ausente), para o diretor Denis Marleau a pele como simulação permite os desdobramentos do animado e do inanimado, da vida e da morte, do real e virtual. Em seu espetáculo Les Aveugles - Les Fantasmagories Technologiques (Fig. 03), ao retirar a visão do corpo, substitui-se a physis ${ }^{1}$ pela techné, remetendo-nos à noção de presença dada pelo fantasma, um eterno loop, uma

\footnotetext{
${ }^{1} \mathrm{~A}$ palavra grega physis pode ser traduzida por natureza, mas seu significado é mais amplo. Referese também à realidade, não aquela pronta e acabada, mas à que se encontra em movimento e transformação, à que nasce e se desenvolve, ao fundo eterno, perene, de onde tudo brota e para onde tudo retorna. Techné é um conhecimento distinto da técnica no sentido geral. Não se limita à pura contemplação da realidade, mas a uma atividade interessada na solução dos problemas práticos, em servir de guia para os homens na sua luta para aperfeiçoar a sobrevivência, na cura de doenças, na construção de instrumentos e edifícios e outros.
} 
repetição da última imagem do morto. A máscara e o fantasma são permeados por dois mundos: o natural e o sobrenatural.

O fantasmático promove o cibridismo, o amálgama ciber e híbrido que caracteriza tecnologias que nos proporcionam habitar dois mundos simultaneamente. Seja real, seja virtual, o comportamento cíbrido liberta-se da rigidez do espaço determinado, o que permite às imagens videográficas alterarem o tempo/espaço e elevarem a figura à potência de entidade. Por sua vez, o corpo como entidade carrega e produz virtualidades, cria um efeito de presença e reorganiza a problemática anterior (corpo obsoleto) numa interpretação pós-humana de controle da natureza, da virtualização corporal como resposta à finitude da existência. Ao contemplarmos a pele-simulação nutrida pelo mascaramento videográfico, reforçamos a ideia de Levy (1996) de atualização², uma invenção a partir de uma dinâmica de forças e finalidades que parecem antecipar um universo predisposto a aliviar o fardo do corpo.

O mascaramento videográfico, com base no binômio ausência/presença, reflete o momento pelo qual caminham os conceitos pós e transhumanos pela busca do domínio total da natureza e das novas relações dentro daquilo que um dia poderá existir: o sonho de transcendência com a máquina, a fusão da vida em uma tessitura biotecnológica.

\section{Paisagem poética, espacialidade cênica}

A utilização de diferentes suportes tais como o corpo, a instalação, a fotografia, o vídeo, o computador nas representações de objetos e figuras tem ampliado os horizontes abarcados pelo conceito pintura de gênero ${ }^{3}$. Um exemplo é a obra Stifters Dinge (Fig. 04), do encenador Heiner Goebbels, uma peça sem atores na qual os elementos cênicos se tornam protagonistas de uma performance teatral. Ao se valer de ações que envolvem luz e elementos da natureza, do cinetismo de artefatos mecânicos e servo-controlados, da presença de vozes acusmáticas (vozes sem corpo), Goebbels joga com a percepção do público, transformando em neblina a chuva que deságua em cena, e fazendo-a dançar ao som de cinco pianos que to-

\footnotetext{
2 Para Pierre Levy (2001), atualização é a criação, a invenção de uma forma a partir da configuração dinâmica de forças. O virtual não se opõe ao real, mas sim ao atual.

${ }^{3}$ A pintura de gênero é um estilo sóbrio, realista, comprometido com a descrição de cenas rotineiras, temas da vida diária, afazeres domésticos, ou até mesmo paisagens. O retrato, a paisagem e a natureza-morta estão relacionados em forma pictórica.
} 
cam sem a presença de pianistas.

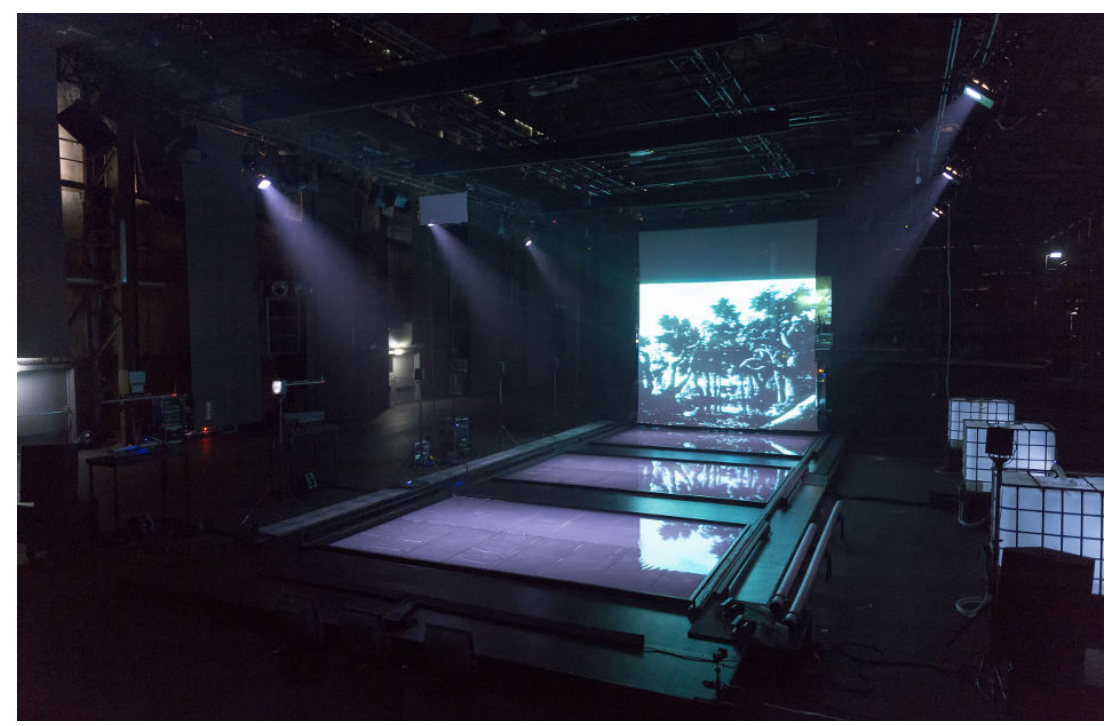

Fig. 04 - Stifters Dinge, Heiner Goebbels, 2013, em

http://www.omm.de/veranstaltungen/festspiele2013/RUHR-2013-stifters-dinge.html

A arte da paisagem é uma das inspirações para essa proposta, na qual o espectador pode traçar o próprio caminho do olhar através de um mosaico de fragmentos e situações. A inexistência da figura humana em Stifters Dinge libera a imaginação do público e estabelece uma poética fundada nas relações perceptivas do palco com a cena, apoiando-se no que Goebbels denomina como estética da ausência, a qual pode ser alcançada pela ação radical de eliminar o ator do palco ou por estratégias que diminuam o seu protagonismo, como deshierarquizar o grau de importância entre esse e os elementos cênicos, dentre outros procedimentos operacionais. Goebbels engendra um drama da percepção: uma ideia artística na qual "o espectador é envolvido num teatro da experiência, em vez de olhar para um drama no qual as relações psicológicas são motivadas por representações de figuras"4 (2010, p. 05).

Por sua vez, o encenador Robert Wilson faz uso do gênero do retrato como recurso poético na exposição Voom Portraits, na qual utiliza como suporte pictórico telas de plasma de alta definição, afixadas às paredes como quadros. Ao se apropriar do

\footnotetext{
${ }^{4}$ The spectator is involved in a drama of experience rather than looking at drama in which psychologically motivated relationships are represented by figures on stage" (GOEBBELS, 2010, p. 05). Tradução livre.
} 
tempo e espaço da linguagem videográfica para elaborar os seus retratos, Wilson acabou criando verdadeiros quadros-vivos, provocantes vídeo-retratos cujas imagens se transformam lentamente diante dos olhos do observador.

Em Voom Portraits (Fig.05), Wilson tende a usar enquadramentos em planos médios ou close-ups ao instaurar o espaço na tela de vídeo, diferente do que se faz tradicionalmente na cena italiana, que normalmente requer a distância do espectador para a apreciação das imagens cênicas, como se esse estivesse diante de uma paisagem (ou de um plano geral). Porém, como Wilson mesmo declara: "Eu quebrei essas regras no teatro e no vídeo, e passei a trabalhar espacialmente com as três formas artísticas tradicionais: retrato, natureza-morta e paisagem" (Wilson, 2012, p. 35).

Quando Wilson concebe a cena como uma "pintura tridimensional faz com que as coisas funcionem como natureza-morta e os atores como retratos de corpo inteiro em movimento" (Lehmann, 2007, p. 133). A divisão e os enquadramentos do espaço cênico levam a plateia a construir um gênero ou outro, o que pode ser feito tanto pelo controle sobre a iluminação quanto pela escolha perceptiva do espectador. Ao tomarmos todo o espectro da composição cênica à nossa frente estamos diante de uma paisagem em contínua transformação, onde atores e objetos são organizados de maneira que os espectadores percebam as tensões entre as formas e criem as suas próprias interpretações.

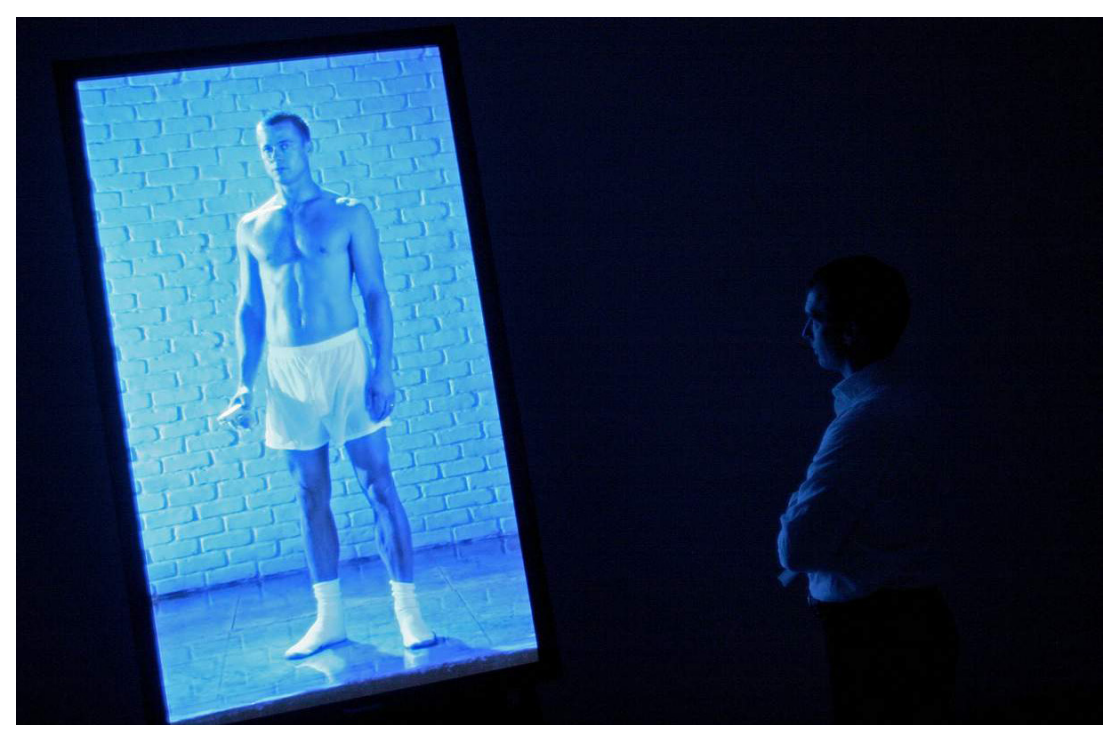

Fig05 - Voom Portraits, Robert Wilson (2007, em http://www.justjared.com/photo-gallery/2416975/brad-pitt-boxers-03/ 
Os corpos nas telas dos Voom Portraits são apenas imagens, e assim como as vozes gravadas e reproduzidas por alto-falantes em Stifters Dinge, produzem um efeito sobre o espectador que evoca a presença dos corpos físicos. Portanto, como nos diz Gerald Siegmund (2007a, 2007b), o que na verdade o público vê, ouve ou percebe é a ausência: uma lacuna que não é exatamente uma falta, mas sim, um lugar ao qual o sujeito passa a existir por meio da instauração de um espaço para seu desejo. Justamente porque existe essa ausência, os sentidos se espacializam e o ambiente inteiro no qual o espectador (e o ator) se encontra torna-se parte da sua corporalidade. Os elementos cênicos se conectam embora estejam em diferentes pontos do ambiente, num intercâmbio de afetos entre a plateia e o palco, configurando uma estrutura recursiva, que retorna incessantemente sobre si mesma num processo de realimentação, e que provoca a dobragem dos espaços - como o intrincado enovelar de um labirinto que cria cavidades, depressões, e lacunas - configurando um lugar privilegiado para o desenvolvimento de relações do sujeito com o mundo. Essa estrutura tende a se desenvolver espacialmente de forma autônoma, nas correspondências e nos pontos de contato, passando a dar mais relevância à dimensão visual da cena, em que as leituras e interpretações do espectador, e as interações entre os elementos em cena, promovem os atravessamentos e constituem sentidos conflitantes ou harmoniosos.

\section{Em conclusão}

Na cena contemporânea, ausência e presença são redimensionadas pelos dispositivos tecnológicos de virtualização da vida, capazes de criar realidades e tempos distintos do aqui e agora. Sob essa perspectiva, os territórios dramatúrgicos se configuram pela utilização de aparatos em cena e na articulação da própria estrutura textual. As artes da cena colocam em jogo o corpo, quer pela sua presença física quer por arranjos que possibilitam a pele como tela ou simulacro. O espaço é problematizado e engendra um (não) território que implica o espectador na relação com a obra em diversos aportes.

A friç̧ão entre teatro e tecnologia instaura o que Rancière chamou de desaparecimento do performer e aparecimento do público. Na busca por um espectador ativo, acabou-se chegando ao espectador emancipado, que passa a questionar a oposição entre olhar e agir. O espectador não só olha, mas vai além, "ele observa, 
seleciona, compara, interpreta. Relaciona o que vê com muitas outras coisas que viu em outras cenas, em outros tipos de lugares" (2012, p. 17).

Performer e espectador, acima de tudo, são intérpretes e tradutores ativos do que veem e do que sentem, eles são e se fazem presentes mesmo vislumbrando a ausência. Ambos dialogam com o aparato midiático constituindo uma co-presença, aceitando a projeção daquilo que já foi presente como corporificação de uma realidade (a)temporal.

Para além dos cruzamentos de linguagens, podemos dizer que, através dos diversos aportes tecnológicos, alcançamos uma cena teatral virtual, mediatizada, que coloca em discussão não só o corpo do artista e a presença do espectador, mas também a forma da sensibilidade cênica contemporânea.

\section{Referências}

BYUNG-CHUL, Han. A sociedade da transparência. Lisboa: Relógio d'Água Editores, 2014.

DANAN, Joseph. Qu'est-ce que la dramaturgie? Paris: Actes Sud-Papiers, 2012.

GOEBBELS, Heiner. Aesthetics of Absence: questioning basic assumptions in performing arts. In: Heiner Goebbels, Artist-in-Residence, Cornell University: Cornell lecture on contemporary aesthetics, march 2010. Nova York: Cornell University, 2010. p. 1-20. Disponível em: http://igcs.cornell.edu/home/visitors/aesthetics. Acesso em: 26 ago. 2015.

HAAR, Michel. A obra de arte. Ensaio sobre a ontologia das obras. Rio de Janeiro, Difel, 2007.

HEIDEGGER, Martin. A obra de arte. In: Caminhos de Floresta. Tradução Irene Borges-Duarte e Filipa Pedroso. Lisboa: Fundação Calouste Gulbenkian, 1998.

LEHMANN, Hans-Thies. Teatro pós-dramático. São Paulo: Cosac Naify, 2007.

LES FANTASMAGORIES TECHNOLOGIQUES. Denis Marleau. Châlons-en-Champagne: La Comète, 2009. 1 peça de teatro.

LÉVY, Pierre. O que é virtual? São Paulo: Editora 34, 2001.

LIFE ITSELF IS NOT ENOUGH. Fred Eerdekens. Paris: Magda Danysz Gallery, 2012. 1 fotografia. 
RANCIÈRE, Jacques. O espectador emancipado. São Paulo: WMF Martins Fontes, 2012.

SANTOS, Milton. Por uma outra globalização: do pensamento único à consciência universal. S. Paulo/Rio de Janeiro: Record, 2001.

SIEGMUND, Gerald. Apparatus, attention, and the body: the theatre machines of Boris Charmatz. In: TDR/Theatre Drama Review, Massachusetts, v. 51, n. 3, p. 124-139, outono, 2007a.

SIEGMUND, Gerald. Experience in a space where I am not: staging absence in contemporary dance. In: Discourses in dance, Londres, v. 4, n. 1, p. 77-95, 2007b.

VIDEOTANGO. Otávio Donasci. Rio de Janeiro: Festival de Arte Performance Brasil, 2011. 1 vídeo performance.

WILSON, Robert. Voom Portraits. São Paulo: SESC-Pinheiros, 2008.

WILSON, Robert. Robert Wilson: space time. Milano: Silvana Editoriale, 2012. 